\title{
Randomised controlled trial comparing prednisolone alone with cyclophosphamide and low dose prednisolone in combination in cryptogenic fibrosing alveolitis
}

\author{
M A JOHNSON, S KWAN, N J C SNELL, A J NUNN, J H DARBYSHIRE, \\ M TURNER-WARWICK \\ From the Department of Thoracic Medicine and the Medical Research Council Cardiothoracic Epidemiology \\ Group, Cardiothoracic Institute, Brompton Hospital, London
}

\begin{abstract}
In a randomised, controlled study alternate day prednisolone with an initial high dose phase ("prednisolone only series") has been compared with cyclophosphamide plus alternate day low dose prednisolone ("cyclophosphamide-prednisolone series") in 43 patients with previously untreated fibrosing alveolitis (five patients had received prednisolone in minimal dosage). In the prednisolone only series prednisolone $60 \mathrm{mg}$ daily was given for one month and then reduced by $5 \mathrm{mg}$ a week to $20 \mathrm{mg}$ on alternate days or the minimum dose to maintain early improvement. Patients in the cyclophosphamide-prednisolone series received 100,110 , or $120 \mathrm{mg}$ cyclophosphamide daily (depending on body weight) plus $20 \mathrm{mg}$ prednisolone on alternate days. Treatment was continued indefinitely, or changed to the alternative regimen if the patient deteriorated, failed to improve, or developed drug toxicity. For response to treatment (as judged by change in breathlessness score, radiographic appearance, and lung function) patients were classified as improved, stable, or deteriorating. Deaths from cryptogenic fibrosing alveolitis were also analysed.

Improvement had occurred at one or more assessments in seven of the 22 patients in the prednisolone only series and in five of the 21 patients in the cyclophosphamide-prednisolone series. At three years, however, only two of the 22 patients in the prednisolone only series were still improved and three stable, compared with one and seven of the 21 patients in the cyclophosphamideprednisolone series (three of the seven had stopped treatment because of toxicity).

Life table analysis suggested better survival in patients in the cyclophosphamide-prednisolone series but this was not significant. At three years 10 of 22 patients in the prednisolone only series had died compared with three of 21 patients in the cyclophosphamide-prednisolone series. With death or failure of first treatment regimen as outcome there was a significant advantage to the patients having cyclophosphamide-prednisolone. This advantage was explained in part by the better lung volumes in this group on admission. After allowance had been made for total lung capacity (TLC), no other factor was predictive of outcome. Analyses of subgroups according to TLC on admission showed that patients with a TLC below $60 \%$ predicted did badly and those with a TLC of $80 \%$ or more predicted did well with both regimens. Patients with an initial TLC of $60-79 \%$ predicted did better with the cyclophosphamide-prednisolone regimen. Side effects were uncommon in both series and those due to cyclophosphamide resolved when treatment was stopped. The combination of cyclophosphamide with prednisolone may be an alternative to prednisolone alone with an initial high dose phase. Many patients, however, failed to respond to either treatment.
\end{abstract}

Address for reprint requests: Professor M Turner-Warwick, Department of Thoracic Medicine, Cardiothoracic Institute, Brompton Hospital, London SW3 6HP. 
Introduction

Cryptogenic fibrosing alveolitis (idiopathic pulmonary fibrosis) is a disorder with an almost invariably poor prognosis. ${ }^{\prime}$ Untreated patients in a previous retrospective study had a median survival of only 54 months. ${ }^{2}$ In uncontrolled studies a small proportion of patients have been found to respond to treatment with corticosteroids, and this response was also related to improved survival time. ${ }^{1-7}$ The features associated with steroid responsiveness in the retrospective study were younger age, female sex, and a more cellular histological appearance (though not necessarily characteristic of desquamative interstitial pneumonia). ${ }^{2}$ Improvement has been reported to be associated with a greater number of intra-alveolar large mononuclear cells and less fibrosis in biopsy specimens.' Some patients respond only transiently to treatment with high dose corticosteroids and most show no response. Long term treatment with high dose corticosteroids is complicated by side effects, some of them serious and causing permanent sequelae. Alternative forms of treatment for this disorder are therefore desirable.

Some reports of uncontrolled studies have indicated that cyclophosphamide and other immunosuppressant drugs may be as effective as corticosteroids and may have less serious side effects. Cyclophosphamide, azathioprine, and chlorambucil have all been reported to produce objective evidence of improvement. . $^{8-13}$ Patients have also been reported to respond to immunosuppressant agents after having failed to respond to steroids. ${ }^{911-13}$ The addition of an immunosuppressant agent has led to further improvement in corticosteroid responsive patients. ${ }^{9}$

The aim of this randomised controlled study was to compare the efficacy and side effects of cyclophosphamide in combination with low dose alternate day prednisolone with those of alternate day prednisolone alone (including an initial high dose phase) in patients with previously untreated fibrosing alveolitis $(<30 \mathrm{mg}$ prednisolone for one month).

\section{Methods}

\section{PATIENTS}

All patients with cryptogenic fibrosing alveolitis who were referred to the department of medicine at the Brompton Hospital during 1980-4 were admitted to hospital and assessed for entry into the study. Patients who had ever previously received prednisolone in a dose of $\mathbf{3 0 ~ m g ~ d a i l y ~ f o r ~ m o r e ~ t h a n ~ o n e ~ m o n t h ~ w e r e ~ n o t ~}$ eligible, nor were patients who had received an immunosuppressant drug. The diagnostic criteria for cryptogenic fibrosing alveolitis were those of TurnerWarwick and Haslam ${ }^{14}$ and the diagnosis was confirmed whenever feasible by open lung biopsy. Patients were excluded if they were positive in the avian precipitin test or had a relevant occupational exposure. Patients were not eligible if they were pregnant or wished to have children in the near future, or if they had coincidental malignant disease, diabetes mellitus, or active tuberculosis. In addition, patients were not eligible if either regimen was contraindicated on clinical grounds.

Of the 78 patients referred, 45 were eligible for admission to the trial, of whom 43 were enrolled. Of those excluded, 19 had previously received treatment, seven were not suitable for one or other regimen, and seven had other final diagnoses. Of the 43 patients enrolled, 38 had never been treated, three had received $30 \mathrm{mg}$ prednisolone or less daily for one month or less in the past but were no longer having any treatment, and two patients (one in the high dose prednisolone and the other in the cyclophosphamide plus prednisolone series) were receiving prednisolone $5 \mathrm{mg}$ daily and $10 \mathrm{mg}$ daily respectively at the time of enrolment. Thirty three patients had had an open lung biopsy, two a drill biopsy, and one a transbronchial biopsy. On entry to the study patients gave their informed consent and the approval of the ethical committee was obtained. Patients were allocated at random to treatment with one of the two following regimens (table 1): 1 Prednisolone alone Initially given in high dosage (according to weight) and reducing to an alternate day maintenance dose: patients weighing $60 \mathrm{~kg}$ or moreprednisolone $60 \mathrm{mg} /$ day for four weeks, then reducing

Table 1 Pretreatment characteristics: clinical details

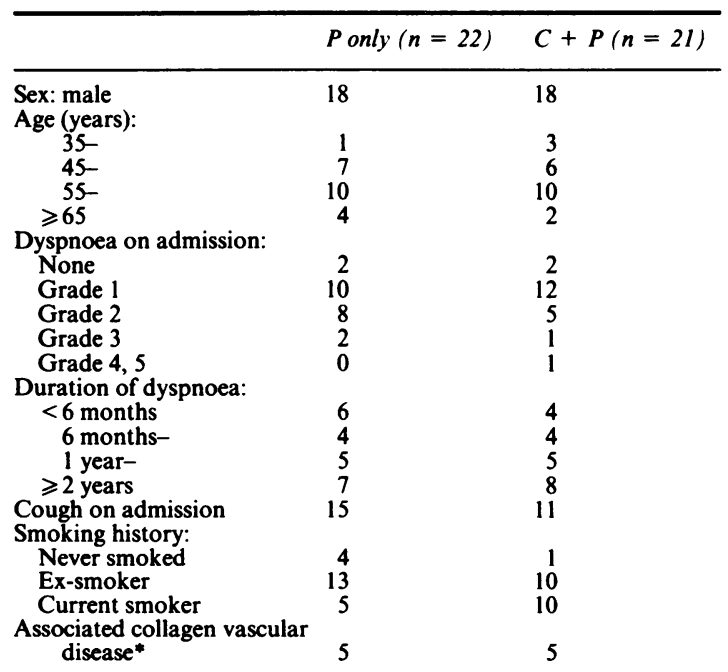

*Prednisolone only group: polyarthritis, 3 cases; Sjögren's syndrome, 1; polyarthritis and Raynaud's phenomenon, 1 . Cyclophosphamide plus prednisolone group: rheumatoid arthritis, 1; Raynaud's phenomenon and polyarthritis, 1; Raynaud's phenomenon, 2; polyarthritis, 1.

$\mathrm{P}$-prednisolone; $\mathrm{C}$-cyclophosphamide. 
by $5 \mathrm{mg} /$ day each week to a maintenance dose of $20 \mathrm{mg}$ on alternate days (the dosage was adjusted occasionally to maintain optimum improvement); less than $60 \mathrm{~kg}$ - prednisolone $1 \mathrm{mg} / \mathrm{kg}$ for four weeks, reducing by the same schedule as patients over $60 \mathrm{~kg}$ to $20 \mathrm{mg}$ on alternate days.

2 Cyclophosphamide plus prednisolone Cyclophosphamide dose according to weight: $70 \mathrm{~kg}$ or more $-120 \mathrm{mg} / \mathrm{day} ; 60-69 \mathrm{~kg}-110 \mathrm{mg} /$ day; less than $60 \mathrm{~kg}-100 \mathrm{mg} /$ day. All patients had prednisolone $20 \mathrm{mg}$ on alternate days.

The aim of the study was to maintain patients on their allocated treatment regimen for at least six months, but if there was clear evidence of physiological, radiological, and symptomatic deterioration before this patients were to be changed to the alternative regimen. Change of treatment was so far as clinically reasonable determined by the criteria set out below under "Data analysis." An attempt to assess bias in management is described in the discussion.

At the initial hospital assessment a clinical history was obtained and a full examination undertaken. Breathlessness was recorded on a six point scale $(0$ none, 1-breathless after two flights of stairs, 2breathless after one flight of stairs, 3-breathless on the flat at own pace, 4 breathless on minimal exertion, 5-breathless at rest).

Pulmonary function measurements included forced expiratory volume in one second $\left(\mathrm{FEV}_{1}\right)$ and forced vital capacity (FVC) (Ohio spirometer), total lung capacity (TLC) (plethysmography: Pulmostar SMB, Fenyves and Gut), single breath pulmonary diffusing capacity for carbon monoxide (transfer factor, TLCO) (model B transfer test apparatus, PK Morgan, Chatham), and this value adjusted for volume of ventilated lung (transfer coefficient, Kco). All lung function measurements are presented as percentages of the predicted values for sex, age, and height. ${ }^{16}$

Patients carried out a standardised progressive exercise test on a bicycle ergometer to the maximum tolerated load, with blood gas measurements before the start of the exercise and at the end. They also carried out a 12 minute walking test with standard instructions. ${ }^{15}$

Radiographic assessment was made with $140 \mathrm{kv}$ chest radiographs. At the end of the study all films were scored according to a modified UC-ILO classification by one reader (IHK) without access to any clinical information. ${ }^{17}$ Profusion scores of $0 / 0-3 / 3$ were recorded for each lung to establish a nine point scale for each lung separately, an 18 point scale overall. The UC-ILO system has been used in other non-occupational lung diseases, with radiographic features similar to those of cryptogenic fibrosing alveolitis. ${ }^{18}$ In addition, the chest radiographs were reviewed in known order, but without knowledge of other clinical details, to assess the amount of change $\stackrel{\tilde{x}}{.}$ from the pretreatment film on a scale of -3 (substan- $\vec{\Rightarrow}$ tial deterioration) to +3 (substantial improvement), $0 \stackrel{\text { 足 }}{\circ}$ being "no change."

Open lung biopsy specimens when available were $\frac{\bar{\sigma}}{\bar{\omega}}$ graded by an independent assessor (BEH) without $\frac{{ }^{\circ}}{\sigma}$

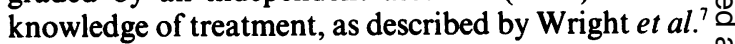
When bronchoalveolar lavage was carried out, the lavage procedure, preparation of samples, and the cell $\vec{O}$ count method were those described previously. ${ }^{19}$

Patients were reviewed one month after starting $\vec{\sigma}$ treatment, at three months and subsequently at three monthly intervals for two years and six monthly $x$ thereafter (or more often if clinically indicated). Patients completed self assessment forms at weekly intervals for the first three months and monthly ${ }_{\infty}^{\circ}$ thereafter, recording cough, sputum, and breathlessness (on the same scale). Clinical response was assessed at each attendance by the chief investigator $\rightarrow$ (MT-W) or deputy and was based on clinical findings, chest radiographs, and pulmonary function measurements, including progressive exercise tests $\vec{\infty}$ with blood gas tension measurements and walking! tests whenever possible. Bronchoalveolar lavage specimens were obtained at the three and 12 month? assessment if the regimen had not been changed. Patients having cyclophosphamide had a full bloodo

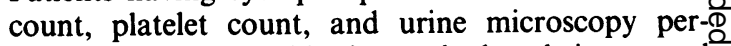
formed at two weekly intervals by their general practitioner.

DATA ANALYSIS

Improvement with treatment was defined as a change from baseline in all three of the following measure $\overrightarrow{0}$ ments compared with pretreatment values (or in two of the three in the exceptional circumstance that one was not available): (1) $10 \%$ or more improvement in. any one of $\mathrm{FEV}_{1}, \mathrm{FVC}, \mathrm{TLC}$, TLCo, or KCO; (2) improvement of one grade or more in direct compar ison of chest radiographs; (3) improvement of ones grade or more in breathlessness score. Deterioration was defined as an equivalent worsening of the same three measurements. Patients classified as having. neither improved nor deteriorated were considered to be stable.

Care was taken to ascertain the cause of deathN్ Patients who died from causes other than fibrosing alveolitis were treated as lost from observation at the point of death. Actuarial survival curves were gen erated and statistical analysis was performed by the log rank method. ${ }^{20}$ All except one of the patients who died from cryptogenic fibrosing alveolitis had change $\$$ their drug regimen before death and therefore time $t \overrightarrow{\mathrm{D}}$ change of regimen or death was also analysed (referre $\$$ to subsequently as "time to failure"). The following were considered in relation to survival and "failure" 
the analyses (Cox's regression analysis being used): age, sex, smoking history, breathlessness grade, duration of breathlessness, radiographic profusion score, sputum production, clubbing, antinuclear antibodies, associated collagen vascular disorder, respiratory indices $\left(\mathrm{FEV}_{1}, \mathrm{FVC}\right.$, TLC, KCO, TLCO, all as percentages of predicted values), and percentages of neutrophils, lymphocytes, and eosinophils in bronchoalveolar lavage specimens. The results of progressive exercise and 12 minute walking tests were not included in this analysis because some patients were too breathless to perform the tests.

\section{Results}

The results are reported for 43 patients, 22 allocated to the prednisolone only group and 21 to the cyclophosphamide-prednisolone group. All have been followed for at least three years and $\mathbf{3 3}$ for five years or more. The two groups were broadly similar on entry to the study in age, sex, duration and degree of dyspnoea, and the presence of arthralgia or associated connective tissue disorder (table 1). In addition, the two groups had similar radiographic shadowing and pulmonary function apart from FVC and TLC, which were on average lower in the prednisolone only series (table 2 ).

\section{IMPROVEMENT}

Of the 22 patients allocated to the prednisolone only regimen, seven were classified as improved at one or more assessments (table 3), five having improved by one month after starting treatment. Four of the seven deteriorated subsequently, one remained stable on the allocated regimen but died from an unrelated cause after three years, and two remained stable on the allocated treatment at four and five years respectively.
Table 2 Pretreatment characteristics: radiographic and pulmonary function

$$
P \text { only }(n=22) \quad C+P(n=21)
$$

Radiographic classification

No of zones affected

$\begin{array}{lrr}1,2 & 1 & 1 \\ 3,4 & 5 & 6 \\ 5,6 & 15 & 14 \\ \text { Profusion score: } & & \\ 0 / 1-1 / 1 & 1 & 2 \\ 1 / 2-2 / 2 & 10 & 7 \\ 2 / 3-3 / 3 & 10 & \end{array}$

Pulmonary function

$\%$ predicted FVC:

$<60$

$60-$

$\geqslant 80$

$\%$ predicted TLC

$<60$

$60-$

$\geqslant 80$

$\%$ predicted TLCo:

$<30$

$30-$

$\geqslant 50$

$\%$ predicted $\mathrm{KCO}$ :

$<50$

$50-$

70

$\geqslant 90$

Total patients

$\begin{array}{rr}5 & 1 \\ 11 & 9 \\ 6 & 11 \\ 9 & 3 \\ 7 & 8 \\ 6 & 10 \\ 3 & 5 \\ 16 & 10 \\ 3 & 6 \\ 4 & 6 \\ 6 & 6 \\ 7 & 5 \\ 5 & 4 \\ 22 & 21\end{array}$

P-prednisolone; C-cyclophosphamide; FVC-forced vital capacity; TLC-total lung capacity; TLCo-transfer factor for carbon monoxide; $\mathrm{KCO}-$ transfer coefficient.

Of the 21 patients allocated to the cyclophosphamideprednisolone regimen, five improved. One patient was first classified as having improved at three months and four patients at the 12 month assessment. Two of the patients subsequently deteriorated between 12 and 24 months and one remained stable at five years. The remaining two patients developed toxicity after two

Table 3 Condition of patients one, three, 12, 24 and 36 months after starting treatment*

\begin{tabular}{|c|c|c|c|c|c|c|c|c|c|c|}
\hline & \multicolumn{10}{|c|}{ Time after starting treatment } \\
\hline & \multicolumn{2}{|c|}{1 month } & \multicolumn{2}{|c|}{3 months } & \multicolumn{2}{|c|}{12 months } & \multicolumn{2}{|c|}{24 months } & \multicolumn{2}{|c|}{36 months } \\
\hline & Ponly & $C+P$ & P only & $C+P$ & P only & $C+P$ & P only & $C+P$ & Ponly & $C+P$ \\
\hline \multicolumn{11}{|l|}{ Continuing on allocated regimen } \\
\hline Improved & $5[5]$ & 0 & 3 & $1[1]$ & $2[1]$ & $4[4]$ & $2[1]$ & 1 & 2 & 1 \\
\hline Stable & $15^{2}$ & 20 & 15 & 16 & 5 & 8 & 4 & 8 & 3 & 4 \\
\hline Deteriorated & 2 & 1 & 1 & 2 & $\mathbf{0}$ & 0 & 0 & 0 & 0 & i \\
\hline \multirow{2}{*}{\multicolumn{7}{|c|}{$\begin{array}{l}\text { Stopped because of toxicity } \\
\text { Changed because of toxicity or other }\end{array}$}} & 0 & 0 & 0 & 3 \\
\hline & & & & & & & 0 & 2 & 0 & 2 \\
\hline Changed because of failure & 0 & 0 & 2 & 1 & 13 & 6 & $\begin{array}{r}0 \\
15\end{array}$ & $\begin{array}{l}2 \\
8\end{array}$ & 16 & $\begin{array}{l}2 \\
8\end{array}$ \\
\hline Died from other cause & 0 & 0 & 1 & 0 & 1 & 1 & 1 & 2 & 1 & 2 \\
\hline Total patients assessable & 22 & 21 & 22 & 21 & $2 i$ & 21 & 21 & 22 & 22 & 21 \\
\hline \multicolumn{11}{|l|}{$\begin{array}{l}\text { Total deaths from cryptogenic fibrosing } \\
\text { alveolitis (all after change of }\end{array}$} \\
\hline treatment) & 0 & 0 & 1 & 0 & 3 & 0 & 6 & 2 & 10 & 3 \\
\hline
\end{tabular}

"Numbers in square brackets are "first time" responders.

†Including one patient (in the cyclophosphamide plus prednisolone group) who changed because she complained about hair loss.

P-prednisolone; $\mathrm{C}-$ cyclophosphamide. 
Table 4 Total deaths (to February 1989)

\begin{tabular}{lll}
\hline Cause of death & $P$ only & $C+P$ \\
\hline Cryptogenic fibrosing alveolitis & $11^{*}$ & $8^{*}$ \\
Carcinoma of bronchus & 1 & 2 \\
Cerebral metastases (primary unknown) & 1 & 0 \\
Cardiac causes & 0 & 4 \\
Dissecting abdominal aortic aneurysm & 0 & 1 \\
Cerebral infarction & 1 & 0 \\
Hepatic encephalopathy & 1 & 0 \\
Total deaths & 15 & 15 \\
\hline
\end{tabular}

*Including one patient with coincidental bronchial carcinoma at necropsy.

$\mathrm{P}$-prednisolone only; $\mathrm{C}+\mathrm{P}$-cyclophosphamide plus prednisolone.

years' treatment; cyclophosphamide was stopped and both remained stable at four years.

Twenty four (16 prednisolone only, eight cyclophosphamide and prednisolone) patients were changed to the alternative regimen because of lack of response. Of the 16 initially allocated to prednisolone only, three improved when cyclophosphamide was added, whereas only one of the eight initially allocated to cyclophosphamide and prednisolone, improved with high dose prednisolone.

\section{STABILISATION}

At three years five of the 22 patients in the prednisolone series were either improved or stable and still on their allocated regimen, as were five of the 21 patients allocated to the cyclophosphamide-predni-

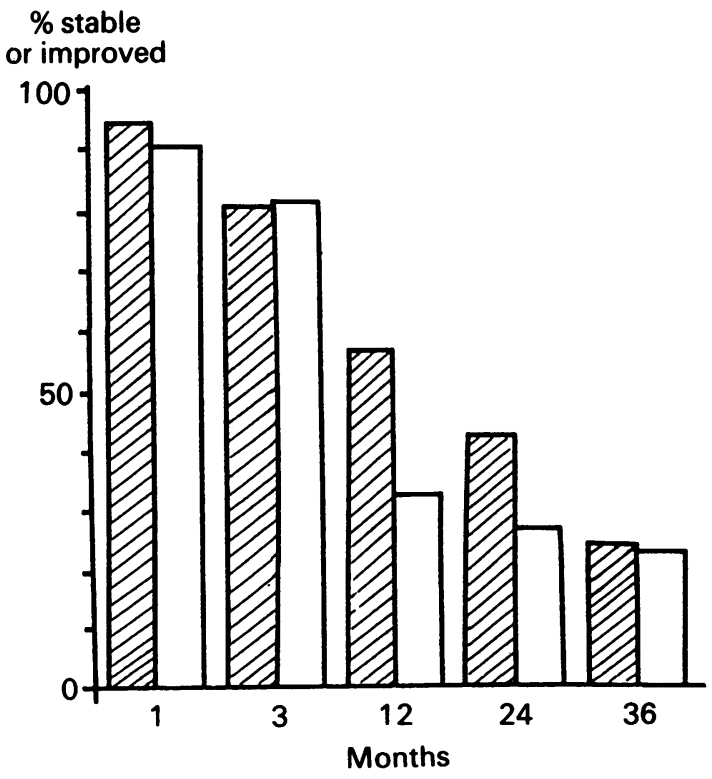

Fig 1 Percentage of patients stable or improved by month of assessment. Group receiving cyclophosphamide plus prednisolone; $\square$ group receiving prednisolone only. solone series (one patient in this series was still on the allocated regimen despite having deteriorated) (fig 1). Three further patients from the cyclophosphamideprednisolone series had stopped their cyclophosphamide because of toxicity but remained stable.

SUR VIVAL ANALYSIS

There was a suggestion of improved survival in क patients allocated to the cyclophosphamide-prednisolone regimen (fig 2 ) but this was not significant ( $p$ $>0 \cdot 1)$.

Analysis of the data with respect to time until failure of the first treatment regimen or death showed that this was significantly longer for the patients allocated to the cyclophosphamide-prednisolone series $(p<0.05)$; at three years, for example, $53 \%$ of the patients initially allocated to cyclophosphamide-prednisolone were still having their allocated treatment or receiving no treatment, compared with $24 \%$ of the patients in the prednisolone only series (fig 3 ).

The only factors significantly associated with time to "failure" in the Cox regression analyses were initial FVC and TLC ( $p<0.05$ for both). Patients with a TLC of $80 \%$ or more of the predicted value did well, with no suggestion of difference between the two regimens (fig 3). Patients with an initial TLC below $60 \%$ predicted did badly in terms of time to "failure" regardless of the initial regimen, all patients having died or changed regimen by two years. Patients with a TLC of $60-79 \%$ predicted did significantly better in the cyclophosphamide-prednisolone series than in the prednisolone only series $(\mathrm{p}<0.05)$.

Survival was also compared for patients initially allocated to the cyclophosphamide-prednisolone regimen and those who were initially allocated to prednisolone only but who were subsequently changed to the cyclophosphamide-prednisolone regimen because of treatment failure. Patients who received cyclophosphamide as part of their first treatment

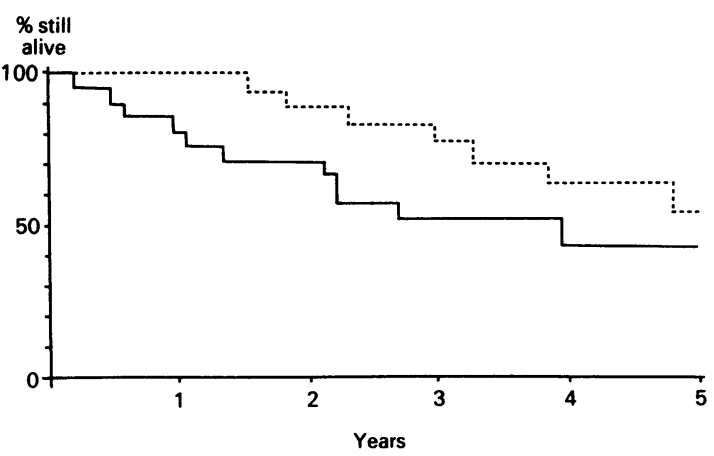

Fig 2 Survival from allocation of regimen until death in 22 patients receiving prednisolone only (-_ 21 cyclophosphamide plus prednisolone (-- - -). 

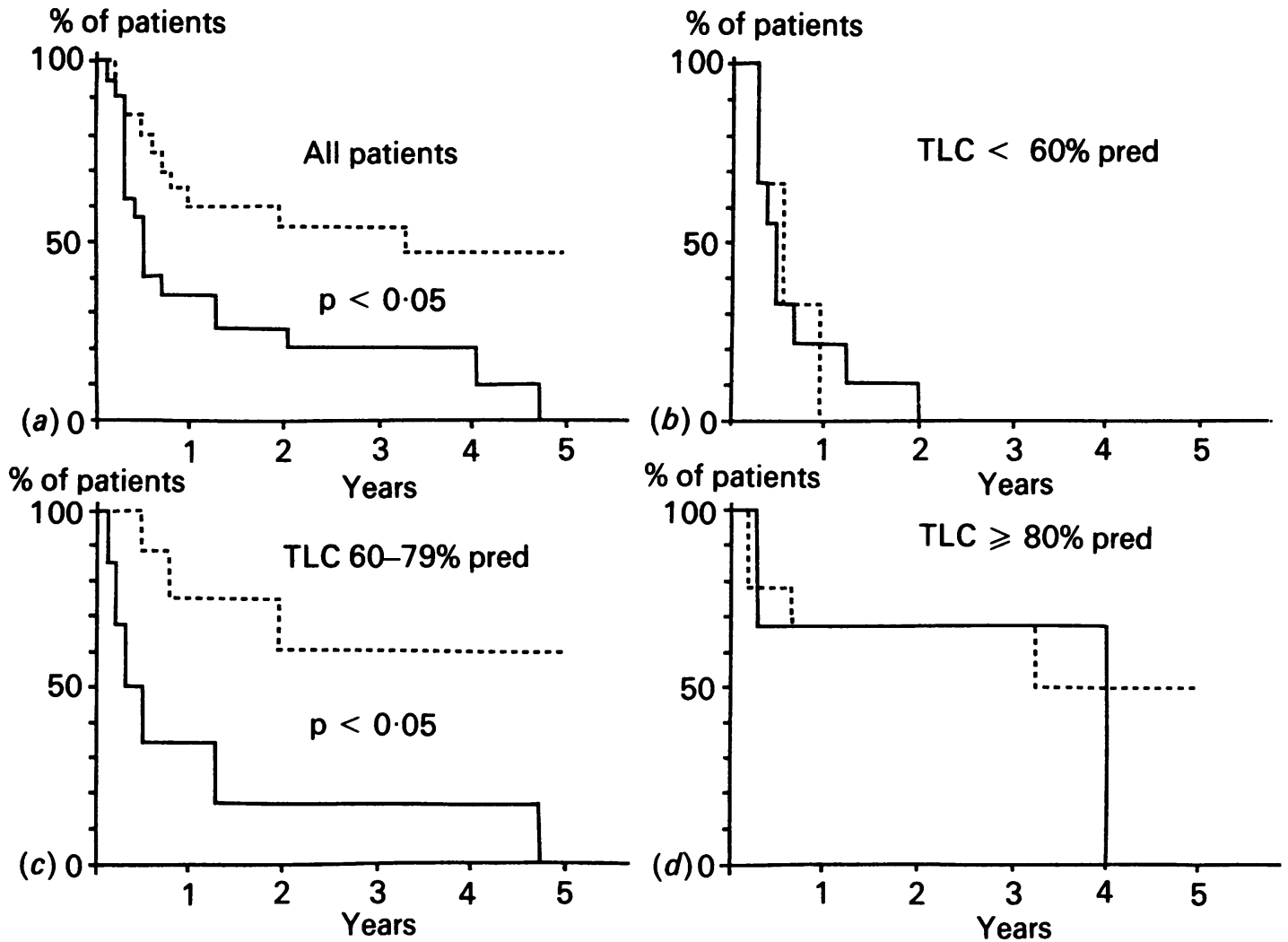

Fig 3 Time from allocation of regimen until change of treatment for failure or death, according to total lung capacity (TLC, $\%$ predicted) before treatment. (a) Twenty two patients initially receiving prednisolone only $(P), 21$ receiving cyclophosphamide plus prednisolone $(C+P)$; (b) $9 P, 3 C+P$; (c) $7 P, 8 C+P$; (d) $6 P, 10 C+P$.

regimen survived longer than patients who received it after failure of the prednisolone only regimen (the difference appears to be entirely accounted for by TLC $\%$ predicted and breathlessness grade at the time of starting cyclophosphamide).

\section{DEATHS}

Of the 22 patients in the prednisolone only series, 15 have died so far (table 4). Eleven died from fibrosing alveolitis, one from carcinoma of the bronchus, one from cerebral metastases from an unknown primary tumour, and the remaining two patients from other causes unrelated to treatment. In the cyclophosphamide-prednisolone series there have also been 15 deaths; eight patients have died from fibrosing alveolitis, two from bronchial carcinoma, and five from other causes unrelated to treatment. At three years 10 of 22 patients in the prednisolone only series compared with three of 21 in the cyclophosphamideprednisolone series had died from fibrosing alveolitis.

Table 5 Cyclophosphamide toxicity in seven patients with cryptogenic fibrosing alveolitis (CFA)

\begin{tabular}{|c|c|c|c|c|c|}
\hline Patient No & $\begin{array}{l}\text { Month } \\
\text { toxicity } \\
\text { started }\end{array}$ & $\begin{array}{l}\text { Month } \\
\text { cyclophosphamide } \\
\text { reduced }\end{array}$ & $\begin{array}{l}\text { Month } \\
\text { cyclophosphamide } \\
\text { stopped }\end{array}$ & $\begin{array}{l}\text { Follow up (months) } \\
\text { after stopping } \\
\text { or reducing } \\
\text { cyclophosphamide }\end{array}$ & Outcome at last assessment \\
\hline $\begin{array}{l}1 \\
2 \\
3 \\
4 \\
5 \\
6 \\
7\end{array}$ & $\begin{array}{r}1 \\
5 \\
6 \\
8 \\
11 \\
14 \\
18\end{array}$ & $\begin{array}{r}2 \\
6 \\
6 \\
12 \\
11 \\
19\end{array}$ & $\begin{array}{r}5 \\
38 \\
29 \\
24 \\
27 \\
33\end{array}$ & $\begin{array}{r}81 \\
1 \\
32 \\
28 \\
25 \\
48 \\
32\end{array}$ & $\begin{array}{l}\text { Stable } \\
\text { Death from CFA } \\
\text { Stable until death (not from CFA) } \\
\text { Death from CFA } \\
\text { Stable } \\
\text { Stable } \\
\text { Stable until death (not from CFA) }\end{array}$ \\
\hline
\end{tabular}


ADVERSE REACTIONS

Evidence of toxicity to cyclophosphamide was reported in seven patients receiving cyclophosphamide between one and 18 months after starting treatment (table 5). Six had haematological toxicity with a reduced neutrophil or platelet count and one had microscopic haematuria. Six of the seven patients had their cyclophosphamide stopped; the seventh patient was able to continue with cyclophosphamide but in a reduced dose. Neutrophil and platelet counts returned promptly to normal and the microscopic haematuria settled. Even though they stopped treatment the lung disease remained stable in five of the seven patients (and has remained stable in one after 81 months' further follow up).

One patient in the cyclophosphamide-prednisolone series developed osteoporosis after 26 months of treatment and prednisolone was discontinued. Six patients developed side effects in the prednisolone only series; one developed osteoporosis, four diabetes mellitus, and one epigastric discomfort. All six, however, continued the treatment.

\section{Discussion}

The design of therapeutic trials in patients with cryptogenic fibrosing alveolitis poses several problems. The condition has a poor prognosis and several uncontrolled studies have suggested that individual patients may improve either with oral corticosteroids or with immunosuppressant drugs, including cyclophosphamide ${ }^{11-13}$ and azathioprine. ${ }^{6 / 13}$ On the basis of these reports we considered it unethical to include a placebo group, particularly as spontaneous improvement of cryptogenic fibrosing alveolitis is very uncommon. ${ }^{1}$ As the disease is rare the number of cases available for study is small and trials of more than two therapeutic regimens confined to one centre would not be practical. Previous (uncontrolled) studies have suggested that about $20 \%$ of patients may be expected to improve with corticosteroids, ${ }^{21}$ so it was likely that many patients would need to transfer to the alternative regimen of cyclophosphamide. In our previous experience improvement in individual patients with cyclophosphamide occurred in those who had been receiving prednisolone as well. Because of this and to avoid complications of prednisolone withdrawal we elected to use a regimen of cyclophosphamide with a small dose of prednisolone $(20 \mathrm{mg}$ on alternate days). We cannot therefore be sure that the results of the cyclophosphamide regimen reported here are due to this drug alone; from previous experience, however, $20 \mathrm{mg}$ of prednisolone on alternate days from the beginning of treatment seems unlikely to have a major independent influence on the course of the disease. The reducing protocol for the prednisolone only regimen could be criticised on the $\stackrel{\mathscr{N}}{x}$ basis that the maintenance dose $(20 \mathrm{mg}$ on alternate $\overrightarrow{\vec{F}}$ days) was too low. This level, however, was reached only after much larger doses had been given on a daily basis for at least three months, during which time the $\overline{\bar{N}}$ patients had been assessed for improvement on at least $\vec{\nabla}$ two occasions.

The population referred to this tertiary referral कै hospital for assessment may be biased towards those $\overrightarrow{0}$ with more severe disease. There was almost invariably a delay before patients were referred for initial evalua- $\vec{\omega}$ tion. In addition, some physicians had treated patients with low doses of prednisolone before referral and $x$ they may not have sent patients who responded to $f$ similar doses of prednisolone for evaluation. Indirect $f$ evidence that some of the potentially most steroid $\underset{\infty}{N}$ responsive patients may not have been referred to us is suggested by the fact that only four of the 40 patients who underwent bronchoalveolar lavage had an $\vec{\nabla}$ increased lymphocyte count in pretreatment lavage specimens. Recent evidence suggests that this group is the most responsive to corticosteroid treatment. ${ }^{22}{ }^{23} \mathrm{An} \vec{\varnothing}$ additional indication of this bias is the predominance $\subseteq$ of men, as they have been shown to respond less well. ${ }^{2}$. For ethical reasons we excluded younger patients who intended having children in the near future from the random allocation. This prevented us from observing the value of cyclophosphamide in such patients.

We could not use a fully double blind design because $\stackrel{\varrho}{\Rightarrow}$ it was judged unethical to require patients taking high $\frac{0}{3}$ dose prednisolone to have fortnightly blood tests. The obvious facial mooning caused by prednisolone treat $-\frac{7}{0}$ ment and the macrocytosis of those having cyclophosphamide would in any case have made the treatment regimens obvious. In a trial which is not double blind it is crucial that those responsible for management do not introduce a bias towards one or other regimen by 3 using different criteria when making the decision to 8 change a patient to the alternative limb of the trial. The possibility of such bias was examined during the 의 course of the trial. Unnamed charts were constructed from the collected data, including results of radiographic change (assessed independently), pulmonary function measurements, and patients' serial self assess- $\sigma$ ments. The clinical supervisor was then asked to $N$ decide on the basis of these data, and without $\mathrm{N}$ knowledge of which drug was being used at the time, whether a change in the drug regimen should have been made at various time points. In this analysis there was no suggestion that the decisions on whether to $\cong$ change regimen that were made on the basis of the reconstructed clinical information were different from

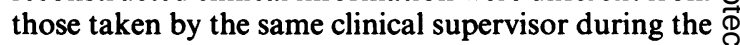
course of the trial.

The problems of maintaining any trial over many $\stackrel{8}{\circ}$ years are formidable, particularly when the number of 
patients is small so that a full time coordinator cannot be justified and the trial is maintained by a succession of junior clinical staff. Only one subject, however, is no longer being followed up in the study and this was because she refused to attend. Continuity was maintained by the clinical supervisor and the coordinating team in the Medical Research Council unit, in particular the clerical staff who supervised data collection on a day to day basis.

While the evidence from the group analyses favouring either of the two regimens is not substantial, it is consistently in favour of cyclophosphamide. Patients being treated with cyclophosphamide did significantly better in terms of remaining on their allocated treatment regimen than those treated with high dose corticosteroids. In both groups time to "failure" was associated with initial TLC expressed as a percentage of the predicted value. Patients with a TLC of $80 \%$ or more did well and those with a low initial TLC (less than $60 \%$ ) did badly on both regimens. Although it is possible that the subgroup with a TLC of $80 \%$ or more would have survived without treatment, this finding suggests the importance of treating patients early without waiting for subjective or objective evidence of deterioration. This suggestion is supported by the observation of better survival of patients allocated first to the cyclophosphamide-prednisolone group than of those who received cyclophosphamide only after they had deteriorated on the prednisolone only regimen. Patients presenting with a TLC of $60-79 \%$ predicted did better in terms of time to "failure" in the cyclophosphamide-prednisolone series than in the prednisolone only regimen; whether this is a chance finding or reflects a subgroup of patients responding preferentially to cyclophosphamide requires formal testing in a larger number of patients.

A further important observation from this study is that patients who responded to corticosteroids were likely to do so by one month after starting treatment, whereas patients on the cyclophosphamide-prednisolone regimen improved more slowly, often showing gradual improvement in lung function over many months. These observations are important to clinicians attempting to monitor response in their patients. A few patients responded to the alternative treatment after failing on their allocated regimen, suggesting the value of trying both treatments.

Patients who received cyclophosphamide in the first treatment regimen did better than patients who received it after having failed on high dose corticosteroids. This is almost certainly due to deterioration that had occurred by the time of the change, because the difference disappeared when allowance was made for differences in TLC and grade of breathlessness. When these independent variables were excluded the effect of the order of treatment regimen was not significant.
There is obviously concern about the use of long term cyclophosphamide because of potential side effects. The dose of cyclophosphamide used in this study was moderately low, but six patients developed a fall in the neutrophil or platelet count and one developed microscopic haematuria. In all patients these effects were fully reversed when the drug was reduced or stopped. Interestingly, five of these seven patients remained stable for up to six years after stopping or reducing cyclophosphamide and continuing with low dose prednisolone, suggesting that cyclophosphamide may influence the course of the disease. Hair loss may be another cause for concern in patients receiving cyclophosphamide; although it was reported by a few patients there were no cases of severe alopecia. There did not appear to be any excess incidence of malignancy in the cyclophosphamide series; but the numbers of patients are small and no firm conclusions can be reached as the duration of follow up was relatively short. Few patients in the prednisolone only series had important side effects, although four patients developed diabetes mellitus. No patient had to have corticosteroids discontinued. The low incidence of side effects is probably due to the relatively short time that patients received high dose corticosteroids, maintenance steroids being administered only on alternate days; moreover, the patients were mainly male and thus had a lower risk of osteoporosis than postmenopausal women of the same age.

The findings of this study suggest that cyclophosphamide in combination with low dose prednisolone is at least as effective as a course of high dose corticosteroids followed by an alternate day low dose regimen. Cyclophosphamide in the dose used in this study was associated with limited toxicity, which was rapidly reversible when the drug was discontinued Unfortunately, both drugs are effective only in a small proportion of patients and new treatments for this condition are urgently required.

We acknowledge and thank I $\mathrm{H}$ Kerr for radiographic assessments, B E Heard for histological grading of biopsy specimens, Deborah Johnson and Elizabeth Brodnicki for data collection, and the registrars and senior house officers who were concerned with the trial at the Brompton Hospital for enthusiastic support.

\section{References}

1 Carrington CB, Gaensler EA, Coutu RE, et al. Natural History and treated course of usual and desquamative interstitial pneumonia. N Engl J Med 1978;298:801-9.

2 Turner-Warwick M, Burrows SB, Johnson A. Cryptogenic fibrosing alveolitis: clinical features and their effects on survival. Thorax 1980;35:171-80. 
3 Stack BHR, Choo-Kang YFJ, Heard BE. The prognosis of cryptogenic fibrosing alveolitis. Thorax 1972; 27:535-42.

4 Crystal RG, Fulmer JD, Roberts WC, et al. Idiopathic pulmonary fibrosis: clinical, histologic, radiographic, physiologic, scintographic, cytologic, and biochemical aspects. Ann Intern Med 1976;85:769-88.

5 Murao M. Idiopathic pulmonary fibrosis. Reports of the nationwide research project in Japan [abstract]. In: Proceedings of the 13th World Congress of Diseases of the Chest, 1980.

6 Meier-Sydow J, Rust M, Kronenberger H, et al. Longterm follow-up of lung function parameters in patients with idiopathic pulmonary fibrosis treated with prednisolone and azathioprine or D-penicillamine. Prax Pneumol 1979;33:680-99.

7 Wright PH, Heard BE, Steel SJ, Turner-Warwick M. Cryptogenic fibrosing alveolitis: assessment by graded trephine lung biopsy histology compared with clinical radiographic and physiological features. $\mathrm{Br} J$ Dis Chest 1981;75:61-70.

8 Meier-Sydow J, Rust M, Kronenberger H. Diagnosis and therapy of idiopathic pulmonary fibrosis. Allergol Immunopathol 1980;80:101-9.

9 Winterbauer RH, Hammar SP, Hallman KO, et al. Diffuse interstitial pneumonitis. Clinicopathologic correlations in 20 patients treated with prednisolone/ azathioprine. Am J Med 1978;65:661-72.

10 Turner-Warwick M. Future possibilities of therapeutic intervention. In: Bouhys A, ed. Lung cells in disease. Amsterdam: North-Holland, 1976:329-40.

11 Brown $\mathrm{CH}$, Turner-Warwick $\mathrm{M}$. The treatment of cryptogenic fibrosing alveolitis with immunosuppressant drugs. $Q J$ Med 1971;40:289-302.

12 Meuret G, Fueter R, Gloor F. Early stage of fulminant idiopathic fibrosis cured by intense combination therapy using cyclophosphamide, vincristine and prednisolone. Respir 1978;36:228-33.

13 Weese WC, Levine BW, Kazemi H. Interstitial lung disease resistant to corticosteroid therapy. Report of three cases treated with azathioprine or cyclophosphamide. Chest 1975;67:57-60.

14 Turner-Warwick M, Haslam PL. Antibodies in some chronic fibrosing lung diseases-1. Non organ specific auto-antibodies. Clin Allergy 1971;1:83-95.

15 McGavin CR, Artvinli M, Naoe H, et al. Dyspnoea disability and distance walked: comparison of estimates of exercise performance in respiratory disease. $\mathrm{Br}$ Med J 1978;ii:241-3.

16 Cotes JE. Lung function: assessment and application in medicine. 4th ed. Oxford: Blackwell, 1979.

17 UICC Committee. Cincinnati classification of the radiographic appearances of pneumoconiosis: a cooperative study by the UICC committee. Chest 1970; 58:57-67.

18 Ferris BG. Epidemiology standardisation project: IV. Use of chest radiography in epidemiological studies of ${ }^{\infty}$ non-occupational lung disease. Am Rev Respir Dis 을 1978;118(suppl 6):89-111.

19 Haslam PL, Turton CEG, Lukoszak A, et al. Bronchoalveolar lavage fluid cell counts in cryptogenic fibrosing alveolitis and their relation to therapy. Thorax 1980;35:328-39.

20 Peto R, Pike MC, Armitage P, et al. Design and analysis of randomised clinical trials requiring prolonged observation of each patient. Br J Cancer 1977;35:1-39.

21 Turner-Warwick M. Approaches to therapy. Semin Respir Med 1984;6:92-102.

22 Turner-Warwick M, Haslam PL. The value of serial bronchoalveolar lavage in assessing the clinical progress of patients with cryptogenic fibrosing alveolitis. Am Rev Respir Dis 1987;135:26-34.

23 Watters LC, Schwarz MI, Cherniack RM, et al. Idiopathic pulmonary fibrosis. Pretreatment bronchoalveolar lavage cellular constituents and their relationships with lung histopathology and clinical response to therapy. Am Rev Respir Dis 1987; 135:696-704. 